\title{
MODELS AND THE DYNAMICS OF THEORIES
}

\section{Paulo Abrantes}

U niversidade de Brasília abrantes@unb.br

\begin{abstract}
A bstract: This paper gives a historical overview of the ways various trends in the philosophy of science dealt with models and their relationship with the topics of heuristics and theoretical dynamics. First of all, N. C ampbell's account of analogies as components of scientific theories is presented. Next, the notion of 'model' in the reconstruction of the structure of scientific theories proposed by logical empiricists is examined. This overview finishes with M. H esse's attempts to develop C ampbell's early ideas in terms of an analogical inference. The final part of the paper points to contemporary developments on these issues which adopt a cognitivist perspective. It is indicated how discussions in the cognitive sciences might help to flesh out some of the insights philosophers of science had concerning the role models and analogies play in actual scientific theorizing.
\end{abstract}

Key words: models, analogical reasoning, metaphors in science, the structure of scientific theories, theoretical dynamics, heuristics, scientific discovery.

H esse (1976) suggests that different philosophical explications of the roles models play in science correspond to different models of science. As a matter of fact, the explication of scientific modeling became a central issue in the criticism and revision of logical empiricism in the 50's and the 60's.

The critics of the logical empiricist explication of models pointed out that it doesn't capture one of the roles models play in science: that of providing guidelines for the development of theories. $^{1}$ 
CAM PBELL ON THEORIES

The idea that models steer the formulation and development of theories dates back at least to Campbell's book Physics: the elements (1920). Strictly speaking, Campbell doesn't talk about "models", but rather about "analogy".

For Campbell, a theory is "a connected set of propositions" that can be divided into two sets: the "hypothesis" and the "dictionary". The way Campbell defines these different sets of propositions in a theory anticipates, in some respects, the so called 'received' ('standard' or 'syntactical') view of the structure of scientific theories, associated with logical empiricism. ${ }^{2}$

W hat is relevant to my concerns here is, rather, the way in which Campbell's conception of a theory differs from those that were subsequently proposed by the logical empiricists. He argues for the need of a third component in a theory - the "analogy" which steers its "development".

Campbell (1920, p. 129) explicitly distinguishes his position from those that regard analogies simply as "aids in the formulation of a theory", as if they could be "removed and forgotten" once the theory is constructed. Instead, he claims that analogies are "an utterly essential part of theories, without which [they] would be completely valueless and unworthy of the name".

The bottom line of Campbell's argument is that the "meaning" of a proposition includes not only its empirical content, but also the "ideas which are called to mind when it is asserted" (Campbell, 1920, p. 132). In particular, the meaning of a theory is not reducible to the "experimental statements" it implies. A "valuable" theory "evokes ideas which are not contained in the laws which it explains" (p. 132). These ideas are suggested by the analogy and play an essential role in modifications of the "hypothesis" and the "dictionary", required when a theory faces "evidence against" it (p. 134). 
In his reconstruction of the way the kinetic theory of gases has been constructed, Campbell claims that the propositions of the hypothesis have a similarity in form with "the laws which would describe the motion of a large number of infinitely small and highly elastic bodies" in a box. The propositions of the dictionary are then "suggested by the analogy displayed by the propositions of the hypothesis" (p. 128).

Campbell's analogy has more than a formal dimension, though. In this context, it is important to mention his distinction between laws and theories, as well as the related distinction between what a proposition "asserts" and what it "means". A proposition asserts its empirical content. The meaning of a proposition includes not only its empirical content, but also the "ideas which are called to mind when it is asserted" (p. 132).

Campbell claims that a law means what it asserts. The meaning of a theory, however, should be distinguished from what it asserts: its meaning is not reducible to the (meanings of the) experimental statements it implies.

Even in the "imaginary" situation in which a theory might be shown to be logically equival ent to a set of laws, $C$ ampbell argues that the meaning of the theory is still not reducible to what these laws assert. Therefore, "formal relationships" are not all that matters in an analogy, but rather the "meanings" it conveys:

A theory is valuable, and is a theory in any sense important for science, only if it evokes ideas which are not contained in the laws which it explains. The evocation of these ideas is even more valuable than the logical equivalence to the laws. (CAM PBELL, 1920, p. 132)

Campbell argues forcefully against a formalist view of the structure of scientific theories:

In theories [...] there is something over and above the formal constitution, which cannot be expressed as part of the formal 
constitution and yet distinguishes the theory from all possible alternatives. (C AM PBELL, 1920, p. 144).

If this is so, even theories that are known to be false- that is, theories which don't strictly imply (or are not equivalent to) experimental laws- might still be valuable, because of the "ideas that they bring to mind" (p. 132). ${ }^{3}$ The situation is clearly different in the case of laws: if what we guessed to be the statement of a law turns out to be false, there is no value left in asserting it.

A nalogies and the dynamics of theories

The core of a theory is, for Campbell, its hypothesis and the analogy it evokes, so to speak. He claims that the dictionary only "uses the analogy" and its propositions are usually suggested by it. Therefore, changes in the dictionary cannot be taken, strictly, as changes in the theory - they don't affect its "identity".

H owever, changes in the hypothesis- in order to account for inconsistencies between the implications of the theory and laws which are already known- can be taken as changes in the essence (or the core) of the theory and, therefore, be regarded as "evidence against" the latter, since they show "that the original theory was not quite complete and satisfactory" (C AM PBELL, 1920, p. 134). G iven the importance $C$ ampbell attributes to the analogy in his account of theories, he regards this appraisal as not always accurate, since the hypothesis might also be suggested by the analogy. In this case, new ideas are, as it were, potentially contained in the original form of the theory, keeping its identity.

In his reconstruction of the development of the kinetic theory of gases, Campbell shows, for instance, how the idea that molecules have a non-zero diameter was introduced in the hypothesis in order to account for experimental data about the viscosity of gases. $\mathrm{He}$ argues that this modification of the hypothesis was a "natural extension of the old theory" of perfect gases, since the analogy with 
elastic bodies suggested that molecules might have a non-vanishing size (CAM PBELL, 1920, p. 134-135). The modifications that were made in the hypothesis can, therefore, be regarded as confirmations of the (original) theory and not evidence against it.

Campbell has nothing to say, however, about how the scientist comes up with the analogy in the first place. He claims that, in most cases, it is just a lucky guess, "a brilliant idea of the inventor, dictated by no rule" (p. 143).

I'll show that Campbell's idea of an analogy, as a component of scientific theories, had its revival in the 50's as part of the emerging criticism against logical empiricism. Before that, we shoud have a look at the reconstruction of scientific theories proposed by the latter trend in the philosophy of science.

Models ANd THE RECEIVEd VIEW OF THEORIES

A central philosophical problem for the so-called "received view" (RV) of the structure of scientific theories concerned the meaning of the theoretical language. Logical empiricists acknowledged that theoretical language cannot, in general, get its meaning by explicit semantic connections with observational language. In later versions of this view of theories, most theoretical terms get their meaning implicitly through their relationships, in the calculus, to other terms, mostly elementary or observational. O nly the latter are explicitly interpreted by means of correspondence rules.

It is not straightforward to assess the place the notion of "model" had in RV. Logical empiricists borrowed this notion from the study of the semantics of formal languages and applied it to the reconstruction of scientific theories. A "semantic model" is a structure of objects, properties and relations, that satisfy (or realize) the sentences of a calculus. 


\section{Carnap on scientific models}

As early as in Carnap's The logical syntax of language (1937) "model" is employed in this sense. ${ }^{4}$ We find in his works explicit critiques of other roles models are supposed to play in science, associated with aims like "understanding" and "visualization" (of theories). Furthermore, I coudn't find in Carnap's early work, at least, any explicit association between modeling and the issue of theoretical dynamics.

In his paper for the The International Encyclopedia of U nified Science (1939), Carnap addresses the issue of the purported "psychological" role provided by models in the understanding of scientific theories. He mentions the case of the relativity and quantum theories and argues that the present situation, at least in physics, is very different from that prevalent in the 19th century, where "intuitive understanding" was still sought through the building of mechanical models.

Carnap emphasizes that a model has "no more than an aesthetic or didactic or at best a heuristic value, but is not at all essential for a successful application of the physical theory" (C ARNAP, 1939 , p. 210). He claims that in order to apply a theory to nature, it is enough to interpret just the "elementary terms" of the theory: "the interpretation of the other terms is then indirectly determined by the formulas of the calculus, either definitions or laws, connecting them with the elementary terms" (p. 210).

In the introductory lectures on philosophy of science C arnap gave in the late 40's and in the 50's (published in 1966), his target is again models taken as "visual spatial structures", as they were understood in nineteenth-century physics (CARNAP, 1966, p. 176). Visualizability is criticized even more explicitly than in his 1939 paper:

The ability to visualize is a psychological matter, entirely irrelevant to physics. The construction of a physical theory is 
not limited by man's power to visualize; in fact, modern physics has moved steadily away from what can be directly observed and imagined. (CARnAP, 1966, p. 172)

Carnap acknowledges, nonetheless, that visual models can be useful since "the mind works intuitively, and it is often helpful for a scientist to think with the aid of visual pictures" (p. 176). ${ }^{5}$

In these lectures, Carnap addresses, in passing, the issue of the dynamics of theorizing. He says that the interpretation of a "postulate system in physics" in terms of correspondence rules is always "incomplete" and that new correspondence rules can be added. This modification in the "dictionary" (C arnap uses C ampbell'sterminology) doesn't change the "identity" of the theory though, given by its "fundamental laws". H owever, Carnap (1966, p. 237) doesn't tell us how these new correspondence rules are introduced or how "radical changes" might come about, in which the fundamental laws of the theory are themselves modified.

Carnap works out the example of the kinetic theory of gases (like many others before and after him, including Campbell). He describes very briefly the "model or schematic picture" of "particles in constant agitation" and goes on saying that "when the kinetic theory was first developed, many of the magnitudes occurring in the laws of the theory were not known" (p. 241). However, this model is not mentioned to account for the introduction of new correspondence rules in the theory - which are required to link theoretical terms and phenomena, making possible the determination of those unknown parameters and, therefore, the test of the theory. ${ }^{6}$

I must highlight, at this point, that C ampbell was concerned, primarily, neither with visualization nor with understanding, when he argued for an analogy as a component of scientific theories. $\mathrm{He}$ was, rather, looking for a rationale in the modifications a scientist makes in a theory in order to cope with empirical data. 
A new concern with modeling

In the 50's, the work of philosophers of a clear logical empiricist allegiance- such as H utten, Braithwaite, Brodbeck, and $\mathrm{H}$ empel- showed a greater concern with the explication of the role models play in science, yielding improved versions of RV. Those attempts fundamentally accepted C arnap's explication in terms of "semantic models".

The most detailed and elaborate of these attempts is Braithwaite's. Hecharacterizes a "model" as a system of propositions having the same formal structure - the same calculus - as the modeled theory. "Model" and "theory" have, however, different "epistemological" statuses:

[...] in the model the logically prior premises determine the meaning of the terms occurring in the representation in the calculus of the conclusions; in the theory the logically posterior consequences determine the meaning of the theoretical terms occurring in the representation in the calculus of the premises. (Braithwalte, 1955, p. 90)

Braithwaite claims that "similarity in formal structure [...] is all that is required of the relationship of model to theory" (p. 93). $\mathrm{H}$ e cautions against the risk of conflating the model and the theory by taking the model's reference as standing for the theory's reference. The interpretation through models can, at best, play a psychological role in helping to grasp the calculus.

D espite his formalist inclinations, Braithwaite expected that a philosophical reconstruction of scientific theories doesn't "ossify" them; instead, he recognized that theories are, in actual scientific practice, dynamical entities (BAILER-Jones, 1999, p. 27).

The explication Braithwaite provided for scientific models was not able, however, to account for any role they might play in the dynamics of theories. He clearly doesn't accept the criticism to RV voiced, for example, by H esse, herself echoing Campbell: "The 
model may be said to point towards its extension in a way which thinking of the calculus in isolation would not do" (H ESSE, 1962, p. 229).

The semantics of theories: do correspondence rules suffice?

Suppe (1977) showed that some versions of RV (that can be found, for instance, in H empel's and C arnap's later works) actually require an independent semantic interpretation of the theoretical language by means of "mathematical models" ${ }^{8}$ over and above the interpretation provided by correspondence rules.

Suppe's claim presupposes a particular account of the notion of "partial interpretation" of a theory, originally proposed by Putnam (1962, p. 245): "to 'partially interpret' a theory is to specify a non-empty class of intended models. If the specified class has one member, the interpretation is complete; if more than one, properly partial".

An independent semantic interpretation of the theoretical language is required to restrict the class of possible models for the theory (that is, the class of models compatible with the interpretation given by the correspondence rules to low-level terms). This independent extra-observational interpretation presupposes a richer metalanguage: ordinary scientific language.

Part of the meaning of theoretical terms comes from this interpretation in the richer metalanguage; the other part comes indirectly through the correspondence rules. Suppe claims that the meanings of terms like "electron", "electron emission" and so forth are, actually, provided by

extra-observational associations - for example, for electrons there might include various features of the billiard-ball model, various classical intuitions about macroscopic point-masses, and so on. Such features contribute to the meaning of theoretical terms in ordinary scientific language, and it is quite 
likely that without them little progress could be made. But despite their legitimate place as meaning constituents of such terms, such features need not, and usually do not, have observable or testable consequences. (Su PPE, 1977, p. 92)

$\mathrm{He}$ argues that the critics of logical empiricism often miscontrued the intention of the proponents of later versions of RV, as if they didn't accept any independent semantic interpretation of the theoretical language. ${ }^{9} \mathrm{He}$ acknowledges, however, that the possibility of an independent semantic interpretation of the theoretical language is not usually made explicit and, moreover, that philosophers like C arnap and H empel didn't give to this issue the importance it deserves. ${ }^{10}$

This might explain the widespread evaluation of RV as the "conceptual vacuum account" of theories, to use Nickles' terms. In that usual reading, besides "neutral" observation language, in RV no intertheoretic relations (by means of models, analogies etc.) were allowed "to playa genuine cognitive role either in concept formation or in hypothesis confirmation" (NICKLES, 1977, p. 572).

H owever, Suppe's construal of the logical empiricistsintentions in later versions of RV contrasts sharply with N ickles'. Suppe argues, somewhat surprisingly, that [...] the doctrine of partial interpretation commits the final version of the Received $V$ iew (interpreted realistically) [...] to a position very similar to that advocated by Campbell [1920], N agel [1961] and H esse [1965, 1966]. (SUPPE, 1977, p. 96)

H owever, Suppequalifies this claim by distinguishing two kinds of models: "mathematical"11 and "iconic". Carnap's and H empel's versions of RV allow only an (independent) interpretation of the theoretical language in terms of semantic models. N agel's, H esse's and Harré's accounts of theories require not only a semantic but also an iconic model. 
In an iconic model, says Suppe, "a model is a model of some thing or kind of thing, and functions as an icon of what it modelsthat is, the model is structurally similar (isomorphic) to what it models" (Suppe, 1977, p. 97). The example he gives of an iconic model is again the familiar billiard ball model for gases. ${ }^{12}$

Suppe argues, however, that the need for an independent interpretation of the theoretical language is a "Iogical" requirement and should be distinguished from the role iconic models might play in theoretical dynamics. Anyway, he explicitly denies that "mathematical" models can play the role of guidelines for theoretical development. ${ }^{13}$ I conic models might be heuristically fruitful but they aren't essential to theories, in the sense that they aren't required to assure their testability or their explanatory role. $^{14}$

Schaffner concurs with Suppe showing, convincingly, that without an "antecedent theoretical meaning" a theory can't even be tested:

O nly after theoretical terms have been given a relatively precise meaning, by providing a list of some of the important properties of the hypothetically proposed theoretical entities, does it even become possible to consider relevant experiments or observations which might test the theory. (Schaffner, 1993, p. 132-133)

H owever, he departs from Suppe by arguing that since models and analogies are often the basis of this antecedent meaning, they can't be considered as just "heuristic at best" (Schaffner, 1993, p. 132). Schaffner claims that logical empiricists were forced to recognize that the meaning of the theoretical language can't be given only by correspondence rules. Instead, the "admissibility" of those rules depends on the antecedent meaning of the theoretical terms. 
Hempel on analogies

H empel's critiques of the first versions of RV emphasized, in agreement with Suppe's reading, that at least part of the meaning of theoretical terms should rely on an antecedently understood vocabulary.

He claims, however, that this "third component" (H EMPEL, 1977, p. 251) of a scientific theory cannot be conflated with what he calls an "analogical model". H empel defines analogical models as models based on nomic isomorphisms (H EM PEL, 1965, p. 435). ${ }^{15}$

This kind of formal analogy presupposes that the laws that describe two systems have the same form, that is, that they are syntactically identical. The properties of the systems and their underlying physical mechanisms need not be the same for setting up a formal analogy, though. Hempel gives the example of the analogy between $\mathrm{O} \mathrm{hm}$ 's law for the flow of an electric current and Poiseulle's law for the flow of a fluid in a pipe. H empel argues that analogical models, in this sense, can't play any role in providing explanations of phenomena in a new domain.

$\mathrm{H}$ e acknowledges, however, that nomic isomorphisms might play a heuristic role in the context of discovery by suggesting "extensions of the analogy on which it was originally based" (H EM PEL, 1965, p. 441). The use of mechanical models by M axwell is given as an example of this heuristic role. ${ }^{16} \mathrm{H}$ owever, $\mathrm{H}$ empel claims that, in this case, models are not based on a formal analogy only, but are taken as hypothetical representations of "microphysical" structures, like in the kinetic theory of heat. These models are, by and large, what Suppe calls "iconic models".

$\mathrm{H}$ empel discusses, in this context, Campbell'sideas about the structure of theories and the essential role the latter assigns to the analogy. $\mathrm{He}$ reads $\mathrm{C}$ ampbell as if the latter required that, in microstructure theories, the laws of the microphysical structures and processes should be "identical or syntactically isomorphic with a set of laws governing an already well explored field of inquiry" 
(H EM PEL, 1965, p. 442). ${ }^{17} \mathrm{H}$ empel goes on to argue that " $\mathrm{C}$ ampbell fails to establish that analogy plays an essential logic-systematic role in scientific theorizing and theoretical explaining" (p. 445).

However, in this criticism, Hempel presupposes that Campbell's analogy boils down to a nomic isomorphism. Some of Campbell's discussions can, certainly, be seen in this light. $\mathrm{N}$ evertheless, I have emphasized that there is more to Campbell's notion of "analogy" than a mere formal dimension, since it is expected to play a role in steering the development of theories.

\section{CRITICISM OF THE LOGICAL EMPIRICIST EXPLICATION}

Despite Suppe's point that in some versions of RV, as in $\mathrm{H}$ empel's, there is an explicit requirement of an independent semantic interpretation of the theoretical language, the early critiques of logical empiricism in the 50's and 60's hinged rather on the relevance of models to an account of the dynamics of theories.

Toulmin, in his 1953 book, claims that the role of models is not only to give an interpretation of a symbolism, but al so to suggest further questions and to steer the investigation. M odels (understood as representations, icons) are, he says, "deployed". However, Toulmin doesn't offer a detailed account of how this deployment is made, or any discussion of its reliability:

[...] the process by which, as we go along, fresh aspects of the model are exploited and fresh questions given a meaning is a complicated one, and one which needs to be studied in detail for each fresh branch of physical theory if the logic of that theory is to be clearly understood. (TouLMIN, 1953, p. 37-8)

In the 60 s and 70's, we find many other philosophers exploring the same point: Achinstein, $\mathrm{H}$ arre, McMullin and Swanson, among others. 
Achinstein (1968, p. 250), for instance, claims that "models aid in formulating, developing, and understanding theories". He stands against the "semantic theory"18 since it doesn't account for these roles. He lists, among the supporters of the latter, B raithwaite, $\mathrm{N}$ agel, $\mathrm{H}$ empel, Brodbeck and $\mathrm{H}$ utten.

The critiques to the "semantic explication" of "model" were often voiced in terms of a "surplus meaning" or "surplus content" associated with models, which introduces an assymetry in the relationship between model and theory, contrary to the symmetry presupposed by the 'formal' explication of this relationship (as in Braithwaite's or Hempel's accounts). For the model to suggest guidelines for the development of a theory it is not enough just to share a syntactical structure with the latter. In his 1970 book, H arré argues also forcefully that "theory construction is primarily model building" (H ARRÉ, 1970, p. 46-47).

Swanson (1966) argued also against the explication of the relation between a model and a theory as a mathematical isomorphism. In the same vein as Nickles, he claims that in the latter account "models are conceptually vacuous devices". Instead, he claims that in science the relation between a model and a theory is asymmetrical: a model has a "deeper structure" than the theory it is modeling. ${ }^{19}$

Spector (1965) argues that theoretical terms must be (directly) interpreted in terms of a model if extensions and modifications of the theory are to be made non-arbitrarily.

H e develops a criticism of the "semantical system approach" to models, which he associates with Carnap and Braithwaite. Spector claims that Braithwaite's concept of model, for instance, cannot distinguish between different roles models play in science. These roles go from "identities of formal structure"- where there is "no relevant connection between the domain or subject matter of the theory and the domain of the model" - to those in which there is a realist commitment of the physicist toward the model taken as 
a representation of the target system (even if it is an idealized representation).

Spector claims, like H esse (below), that modeling is based on analogical reasoning:

If, however, the observable properties of the domain of the theory- the designata of the observation terms- are similar to the properties of the model represented by these same terms when the calculus is interpreted in the domain of the model, then the possibility arises of comparing the properties of the model represented by the theoretical terms of the calculus with the theoretical objects of the theory. That is we can argue by analogy to the nature of the theoretical properties. (SPECTOR, 1965, p. 131)

Spector asks himself whether this condition could be seen as an "emendation" to Braithwaite's semantic approach. He concludes that, actually, his approach is incompatible with the partial interpretation thesis assumed by the logical empiricist accounts of the structure of scientific theories since to reason analogically

from substantive similarities in the designata of terms in the derived formulas in the model and in the theory to substantive similarities in the theoretical (primitive) properties amounts to a direct interpretation of the theoretical terms in the theory. (SPECTOR, 1965, p. 139)

He mentions Campbell, Harre, Hesse and Putnam as anticipating this conclusion.

I will examine next H esse's work which is, probably, the most systematic effort to flesh out C ampbell's ideas on the role analogies play in theoretical dynamics. 
H esse on scientific modeling

O ne year before Toulmin's 1953 book, H esse argued that one of the main functions of an analogy or model is to suggest extensions of the theory by considering extensions of the analogy, since more is known about the analogy than is known about the subject matter of the theory itself. (HESSE, 1952, p. 291)

In a paper published two years later, she claims that the mechanical models of 19th century physics, like M axwell's, played an important role as "pointers towards future progress" (HESSE, 1954, p. 200). ${ }^{20}$

M any critics of the semantic explication of 'model' (especially in Braithwaite's version) argued that for a model to play the role of a "pointer", it has to share with the theory more than a common (syntactic/ formal) structure. H esse, likewise, makes a distinction between "formal" and "material" analogies. ${ }^{21}$ She attempts to explicate the role of models as pointers in terms of the (classical) analogical argument.

In a nutshell, Hesse's fundamental thesis is that the logical empiricist semantic explication of 'model' cannot provide a rationale for modifications either in the axioms of the theory or in the correspondence rules. She argues that only models based on material analogies can provide this rationale and, therefore, make a theory predictive in a strong sense. ${ }^{22}$

In H esse's account, material analogies presuppose a (pretheoretical) recognition of similarities at an observational level, between two systems or domains: the "source" and the "target". ${ }^{23}$ $\mathrm{H}$ esse calls these similarities the "positive analogy", using a terminology she borrows from Keynes. Even if a source is able, by applying this condition, to provide a model for the target, the source and the target are supposed to differ in many respects, that is, they have a "negative analogy" as well. ${ }^{24}$ 
A model for the target system $\left(\right.$ model $_{1}$ ) is constructed from the representation of the source system $\left(\right.$ model $_{2}$ ) by the elimination (abstraction) of the recognized negative anal ogy. ${ }^{25}$ Billiard balls can be a model for gases if we abstract irrel evant properties of the balls, such as their color. The important point to emphasize here is that the construction of models always involves abstraction.

The positive analogy prompts analogical inferences from the description (theory or representation) of the source to a (tentative) description of the target domain. That is, from the perception of similarities at an observational level, we infer (analogically) that both systems probably share other features as well, comprising their "neutral analogy". In non-trivial cases, the inferred features are nonobservable in the target domain and, therefore, provide prima facie (theoretical) explanations of the manifest behavior of the target system.

W hat $\mathrm{H}$ esse calls the neutral analogy has a fundamental importancefor the constructive role she assigns to scientific modeling. Theories are, for Hesse, dynamic entities and the neutral analogy between a (source) model and a (target) system constitutes, in her terms, its "growing points" (H ESSE, 1966, p. 10; 2000, p. 299-300). ${ }^{26}$

AN ANALYSIS OF HESSE'S APPROACH TO SCIENTIFIC MODELING

Several problems are generated by Hesse's analogical inference approach to the role of models as guidelines for theoretical construction. This might explain why it remained relatively marginal from mainstream philosophy of science. $N$ evertheless, $H$ esse's ideas have resurfaced in the recent interest in analogical reasoning in $\mathrm{Al}$ and CS (Abrantes, 1999). In the following, I will, first of all, highlight some problems suggested by her early account and then indicate how they can be worked out by adopting a new approach.

Should observations play a special role in looking for a potential analogy? 
Some argument has to be provided for the privilege conceded to observations (or, rather, descriptions using observational terms) in assessing the similarity of the source and the target systems. H esse insists, in her 1966 book, that similarities should be figured out "pre-theoretically" since to construct a theory for the target domain is what analogical modeling is all about. Obviously, similarity assessments should not presuppose this theory. But this is not the same as to reject any theoretical bias at all.

The privilege conceded to observations in providing a semantics for scientific theories can be seen as a reminiscence of the logical empiricist strict separation between the theoretical and the observational. From this point of view, meaning should ultimately rest on observational language since the latter is taken to be antecedently understood.

Spector argues that if we "impute observational properties to unobservable objects" by means of analogical reasoning, we cannot anymore accept one of the basic presuppositions of the "semantical system approach", that is, a strict distinction between an observational and a theoretical language (SPECTOR, 1965 p. 139).

The claim that analogical arguments are at the basis of concept formation and meaning ultimately undermines a strict distinction between the observational and the theoretical languages. Through analogical reasoning, a predicate that describes an observed property in the source domain may be (hypothetically) applied to non-observed/able properties in the target domain. ${ }^{27}$ If the constructed target theory is successful, the application of this predicate to non-observed/able entities becomes entrenched and can be, tentatively, further applied to other analogous systems. ${ }^{28}$

A more useful distinction can be made, therefore, between entrenched and non entrenched predicates. Entrenched predicates are "familiar" in the sense that they have been successfully applied to different kinds of systems in the past, and figure in accepted theories. That is, entrenched predicates are those employed in the 
"ordinary" scientific lexicon (which is usually far removed from the language of "ordinary" experience).

Therefore, the distinction between "observable" and "theoretical" terms should not be regarded as absolute. The dividing line can shift from time to time and from science to science. M ellor, writing roughly at the same time as $\mathrm{H}$ esse, highlights that the border line between the observational and the theoretical is al ways relative to a particular domain of application and to a particular stage of scientific development:

To be an observable in a science is to be referred to by a term so enmeshed in that science's law network that its correct application to relevant experience (controlled observation) is taken to be un problematic, direct, not involving interpretation by assuming any particular structure of relations between it and other such terms. (MeLLOR, 1968, p. 288)

A theoretical term, instead, is a term introduced by a new theory and depends on this particular theory to be applicable to experience. However, those theoretical terms can later become entrenched: "terms introduced by a successful theory become part of that science's observation language" (M ELLOR, 1968, p. 288).

M etaphors in science ${ }^{29}$

If this is so, there can't be a strict separation either between the observational and the theoretical languages, or between 'literal' and 'metaphorical' applications of a term, a point acknowledged by H esse herself: "W hat is important, is not to try to draw a line between the metaphoric and the literal, but rather to trace out the various mechanisms of meaning-shift and their interactions" (H ESSE, 1966, p. 166; 1976, p. 8). ${ }^{30}$

Already in her 1966 book, Hesse criticized the deductivenomological account of explanation and argued for a view of explanation as a metaphorical redescription of the domain of the 
explanandum. In her proposal, to explain is to redescribe the explanandum using the language of the explanans what leads to a shift in the meaning of the terms originally used to describe the domain of the explanandum. ${ }^{31}$

From a realist point of view, metaphor has the function of catachresis, as already pointed out by Boyd (1979). The theoretical vocabulary in scientific theories refers to things and properties that are beyond our ordinary experience. So, an ostention theory of meaning - which considers that all meaning is based on experience - cannot account for the role scientific theories play in refering to those things.

Martin \& Harré make also this point, associating it with modeling:

It is the role of catachresis which is, in an indirect way, the reason why metaphor is so very useful in scientific theorymaking, for, as suggested earlier, it is not the model in itself as heuristic device that makes models indispensable in creative theory-making, but the fact that the model gives rise to, 'spins off' a matrix of terminology which can then be used by the theorist as a probative tool. Speaking metaphorically on the basis of a model, a scientist is enabled not only to posit but to refer to theoretical entities by the use of terms which transcend experience in that their semantic context is not fully determined a priori by the empirical conditions for their application. Meaning is not exhausted by the conditions of assertability. (M ARTIN \& HaRRÉ, 1982, p. 101-102). ${ }^{32}$

The large litterature on metaphors provides clues to work out, for instance, some of theinsights we find in C ampbell, especially on the way analogies provide meaning to scientific theories.

Similarity and relevance

A central problem for any account of analogical reasoning concerns the notion of "similarity". Any two systems can be 
perceived as "similar" in an indefinite number of respects and in various degrees. ${ }^{33} \mathrm{G}$ ranting, for the moment, that we have selected a sourceanalog, we need to distinguish those respects (e.g. properties) that are relevant from those that aren't, in mapping it to the target. This is certainly a precondition for the plausible transfer of concepts from this particular source representation to the target.

$\mathrm{H}$ esse was aware of the need for criteria in deciding what the relevant respects are in mapping the source to the target. I will, for the sake of argument, grant H esse's (problematic) requirement that the positive analogy should be established solely on the basis of observation. Given the positive analogy, Hesse proposes, furthermore, that those properties in the source which are causally related to the properties that comprise the (already recognized) positive analogy, should also be taken as relevant in making analogical inferences to the target. These "essential properties" should not be dismissed (that is, they should not be included in the negative analogy), since this would amount to the rejection of the source as a model for the target. ${ }^{34}$

H esse's emphasis on causal relations has a pragmatic and an ontological justification. If the basic aim of science is to set up (causal) explanations for the target phenomena, then the criteria that constrain the selection, the mapping and analogical inferences to the target should give a prominent role to causal relations in the source domain. ${ }^{35}$

Relevance criteria for similarity assessments are, therefore, always relative to a context, that is, to ontological and pragmatic commitments of the scientific community in a particular historical period. This point is recognized, in different ways, by many philosophers.

Kuhn (1977, p. 297-298), for instance, claims that "models [...] are what provide the group with preferred analogies or, when deeply held, with an ontology". Here, the term "model" is used to single out a broad world view. Normal scienceis described, in Kuhn's 
work, as problem solving based on similarity with a set of "exemplars". ${ }^{36}$

Popperian philosophers conceded also a central role to ontological commitments in their reconstruction of scientific practice. Lakatos, particularly, was much more interested in theoretical dynamics than logical empiricists. The development of a scientific research program involves the construction of better (that is, less idealized) models of the phenomena on the guidance of the "positive heuristics" which, in Nickles' words, "amounts to a kind of transducer for converting metaphysical ideas into a progressive series of scientific theories" (NICKLES, 1987b, p. 118). ${ }^{37}$

However, Kuhn and Lakatos are somewhat vague on how ontological commitments shape heuristics and, consequently, theoretical dynamics. M CL aughlin explicitly makes the same point:

For each person, [a Scientific World View] consists of a vast set of beliefs about the world, many of them unconscious, un-articulated or implicit in more overt ones, which serve to define what seems to him/her 'natural' as well as 'odd' in his/ her experience, and thence to pick out or highlight striking or significant features of problem situations, as well as of possible models therefor. (MCLAUGHLIN, 1982, p. 94)

In a note to this passage, $M C L$ aughlin highlights the "affinities" between his notion of "scientific world view", Kuhn's paradigms, Lakatos' research programs and Holton's themata. $\mathrm{M}$ cLaughlin could also have included in this list $\mathrm{H}$ arre's "theoryfamilies" (H arré, 1986). A ctually, since his 1970 book, H arré has been arguing for the role ontological commitments play in scientific modeling:

Plausibility for a model is determined partly by the slowly changing general assumptions of the scientific community as to what the world is really like, partly by the way the model fits in to the particular circumstances for which it was created. (HARRÉ, 1970, p. 50) 
The plausibility of analogical inferences

This problem is a central onein H esse's approach to modeling. She acknowledges, however, that this might be as hard a problem to solve as that of the justification of induction. Its solution is required, though, for replying to the critique that analogical reasoning is unreliable. Braithwaite, for instance, typically says:

Analogy can provide no more than suggestions of how the theory might be extended; and the history of science tells us that while some analogical suggestions have led to valuable extensions of the theory, others have led to dead ends. (BRAithWAite, 1962, p. 230)

It is not enough to reply that analogical arguments - like inductivearguments and other kinds of plausible arguments - cannot support logically necessary conclusions and, therefore, that these conclusions should be vindicated a posteriori (HESSE, 1966, p. 14). Some account has to be provided of the a priori plausibility of analogical inferences. I'll suggest below that this problem should be reformulated in other terms.

\section{ANALOGICAL REASONING AND SCIENTIFIC MODELING}

Cognitive science (CS) research on analogical reasoning helps to make explicit and to articulate many insights from philosophers of science concerning the role played by models in the sciences. Henceforth I will embrace an explicit naturalistic and cognitivist approach, which is noticeable in some of my former comments. ${ }^{38}$

I will address in this final part just a few of the insights discussed above, to give a flavor of the contributions a cognitivist approach can give to the understanding of modeling in actual scientific reasoning.

I have just mentioned that Hesse devoted many efforts to tackling the problem of the validity of analogical arguments that 
supposedly underlie scientific modeling. The foregoing discussion suggests, however, that the reasoning process involved here can't be explicated in terms of a simple kind of inference. ${ }^{39}$

In fact, recent work in C S analyzes analogical reasoning into various elementary sub-processes: the selection of a source, its representation, the mapping of the source and the target representations and, finally, the extension or transfer of the source's representation to the target domain.

A main divergence between different computational simulations of analogical reasoning concerns whether the construction of representations for the source and the target domains might be regarded as an integral part of this kind of reasoning or not. For instance, H ofstadter (1995) criticizes a simulation proposed by $G$ entner (1989) and shows, convincingly, that the construction of representations cannot be separated from the mapping in analogical reasoning. The hard problem for a theory of analogy is to give an account of the construction of representations and the mapping as intertwined processes. ${ }^{40}$

A rtificial Intelligence (AI) implementations have shown that the processing of information is sensitive to the way it is encoded. ${ }^{41}$ We can expect, therefore, that the transfer of information from the source to the target be affected by the way the source and the target are represented. The mapping is also, obviously, dependent on these representations. CS brought to the investigation of reasoning processes in general, and to analogical reasoning in particular, this fundamental result: the various sub-processes of analogical reasoning should not be regarded as autonomous, but as interacting in complex ways. ${ }^{42}$

The claim that analogical reasoning involves a complex reasoning process has also been made in philosophical discussions. Leatherdale, for instance, distinguishes an analogical argument from what he calls an "analogical act": 
[...] it cannot be stressed enough that an analogical act is not in any sense an argument, even though it may well provide a basis for one. Even where it does provide the basis of an argument, it cannot be a purely formal argument on the lines of the logical paradigm of an argument from analogy [...] (Leatherdale, 1974, p. 14-15)

Analogy-making is likened to an act of recognition, or perception, involving "revisualization" or "rerepresentation". ${ }^{43}$ In Al, H ofstadter (1995) champions this analogy- as- perception approach.

O ntological commitments in analogical reasoning

I highlighted previously one of the insights of many philosophers of science that addressed scientific modeling: ontological commitments are involved not only in selecting a particular source analogue for modeling purposes, but also in determining the properties that should betaken into account when the source and the target are likened. I showed also how Hesse faces the problem of relevance in her account of analogical modeling.

A distinctive way to handle this issue is by adopting a topdown approach to similarity. Instead of taking 'similarity' as a primitive notion, as in a bottom-up approach, we should consider 'similarity' as a derivative notion and make explicit the basis of similarity judgments. In a top-down approach, ontological commitments indicate the relevant respects in which the source and the target domains should be compared.

Work in Al on knowledge representation can help to make these ideas more precise and workable. It is worth considering an example of this kind of approach in A ranson et al. (1995). ${ }^{44}$

If we represent a particular ontology (or world-view) by a typehierarchy, then to select a source model amounts to making a (rough) 
hypothesis about what type of system the target is an instance of. The source and the target are supposed to share a certain number of properties, relations etc. corresponding to given types (of systems) at different levelsin this hierarchy. The decision to map only certain respects of the source and the target systems, and to dismiss others, follows from this localization of both systems in a typehierarchy. ${ }^{45}$

A nalogical reasoning can be understood, from this point of view, as a process of representing the model and the modeled systems as instances of the same or of similar types of system. As a result of this rerepresentation, the differences between the source and the target (H esse's negative analogy) are considered as non essential or accidental.

This process often involves the construction of more abstract concepts through an interplay of constraints imposed by the source and the target domains (or, better, their original representations) as well as by the accepted ontology.

For instance, modeling sound phenomena on a description of water waves, involves a procedure for creating a new and more abstract concept of 'wave' that can be instantiated in both domains of phenomena. We have to tell those features of both domains of phenomena that have to be ignored from those that are relevant. If we try to extend the analogy to include light phenomena, the similarities between these realms of phenomena have to be figured out by constructing an even more abstract concept of wave. This abstraction led, historically, to sever the original concept of wave from its connections with the notion of a material medium. The failure to make this step prompted, initially, analogical inferences to the existence of an electromagnetic ether (see DARDEN, 1982, p. 149). ${ }^{46}$

It can, therefore, be helpful to understand analogical reasoning underlying modeling as higher-order categorization. ${ }^{47}$ O ne much discussed problem about categorization is whether it is based on the (pre-conceptual) perception of similarities between different objects or, rather, these similarities are perceived as a result 
of the instantiation of concepts. Categorization actually seems to involve both top-down (that is conceptual) as well as bottom-up (that is perceptual) contraints. Analogical reasoning is, likewise, constrained by the accepted ontology (with its associated conceptual schemes) and by phenomena in both domains.

Similarities between the source and the target are, therefore, not discovered as objective relation ships but are, rather, constructed through a complex reasoning process, where the source and the target descriptions interact in many ways. ${ }^{48} 0$ ne of the consequences of this interaction is a change in the meaning of (familiar) predicates (or terms). ${ }^{49}$ Similarity assessments are not, therefore, the starting point but, rather, the upshot of a process that can be better described as "analogy-making" (H OFSTADTER, 1995).

\section{CONCLUSION}

The main trend in the philosophy of science in the last century disregarded heuristics as worth investigating. "H euristics" (as a topic in methodology) has been associated with an essential irrationality attributed to discovery processes and contrasted with "logics". ${ }^{50}$ This trend found a firm ground in a reconstructivist approach to modeling in science (resulting, itself, in a particular "model of science", as H esse suggested). D espite the many respects in which $H$ esse's and Campbell's accounts of the dynamics of scientific theories depart from that proposed by logical empiricists, they still accepted this dichotomy and struggled to show that models (or analogies) play not only a heuristic but also a logical role in theorizing. ${ }^{51}$

$\mathrm{H}$ euristics became a central concern to those working in AI. ${ }^{52}$ The current interest in analogical reasoning in thisfield corresponds, however, to a shift from universally applicable, formal and contextindependent reasoning strategies, to a knowledge-driven approach, tied to specific bodies of knowledge, influenced by the context the representations, the world view and the goals of the agent. 
Philosophy of science should take advantage of this trend and approach modeling as one of the most important heuristics in scientific activity. ${ }^{53}$

\section{OSMODELOSE AS DINÂMICAS DAS TEORIAS}

R esumo: 0 artigo traça um panorama histórico das várias correntes em filosofia da ciência que lidaram com model os e sua relação com os tópicos da heurística e da dinâmica teórica. Em primeiro lugar, apresenta-se a proposta de N. Campbell de ver analogias como componentes de teorias científicas. Examina-se, em seguida, a noção de "modelo" na reconstrução da estrutura das teorias científicas propostas pelos empiristas lógicos. Esse panorama completa-se com as tentativas de M . H esse de desenvolver as idéias preliminares de $C$ ampbell em termos de uma inferência analógica. A parte final do artigo aponta para desenvolvimentos contemporâneos sobre esses tópicos que adotam uma perspectiva cognitivista. Indica-se como as ciên cias cognitivas poderiam ajudar a materializar al gumas das intuições que os filósofos da ciência tiveram a respeito do papel que modelose analogias desempenham na teorização científica real.

Palavras-chave: Modelos, raciocínio analógico, metáforas em ciência, estrutura das teorias científicas, dinâmica teórica, heurística, descoberta científica.

\section{Notas}

1. The term "model" is ambiguous and is used, by scientists and philosopheres alike, with a plurarity of meanings. These meanings correspond to a plurality of roles models are supposed to play in scientific practice. It is not my aim, in this paper, to give an exhaustive account of these roles but, rather, to focus on one of them. Nonetheless, my discussion, in what follows, will have to deal with different kinds of models, and I hope the context will make clear what their differences are.

2. The notion of "hypothesis" corresponds roughly to a "calculus", and the notion of "dictionary" corresponds to a set of "correspondence rules" or "meaning postulates". Carnap, himself, in his later works, acknowledges Campbell's contribution (CARNAP, 1966, p. 233). He doesn't mention, however, Campbell's notion of "analogy". 
3. The appraisal of the "value" of a theory can, however, vary from individual to individual: "[...] an analogy is a function of the contemplating mind; when we say that one set of propositions is anal ogous to another we are saying something about its effect on our minds; whether or not it produces that effect on the minds of others, it will still have that effect on our own" (C Am PBELL, 1920, p. 144). This claim is made in the context of his discussion of the rolesimplicity plays in choosing an analogy in the case of "mathematical theories". Hence, there is a personal and arbitrary feature in analogies and in our appraisal of their value. H empel (1965) criticizes this subjective aspect of Campbell's analogy.

4. In Carnap's 1942 book we can also read: "For the application [of calculi or postulate sets] in science it is necessary to leave the purely formal field and construct a bridge between the postulate set and the realm of objects. This is usually called constructing models for the postulate set or laying down correlative definitions for it ('Zuordnungsdefinitionen', Reichenbach)" (C ARn AP, 1942, p. 204).

5. We can read in another passage from these lectures: "It must not be forgotten that, both in the history of science and in the psychological history of a creative scientist, a theory has often first appeared as a kind of visualization, a vision that comes as an inspiration to a scientist long before he has discovered correspondence rules that may help in confirming his theory" (CARnap, 1966, p. 245).

6. Surprisingly, when discussing the development of Maxwell's theory, Carnap acknowledges that "the great strength of the new model was revealed in its power to predict, to formulate empirical laws that had not been previously known" (CARnAP, 1966, p. 242). H owever, since C arnap does not specify clearly what counts as a "theoretical model" in this context, I guess 
that, in this particular example, he is simply identifying "model" and 'theory'.

7. We find in empiricist philosophers an ambiguity concerning the nature of models. Sometimes they are presented as a set of entities (non-linguistic things or a structure, by adopting a settheoretic approach). Formally, given two relational systems $S$ and $S^{\prime}$, defined as ordered tuples of sets of objects, properties and relations, $\mathrm{S}$ is said to be "a model for $\mathrm{S}$ " if there is a homomorphic mapping from the objects of $S$ to the objects of $S^{\prime}$ (that is, a mapping that preserves the relations that hold in S). 0 ther times, models are taken to be linguistic objects (a set of propositions). An example of this ambiguity we find in $\mathrm{N}$ agel: "Let $\mathrm{P}$ bea set of postulates; let $\mathrm{P} *$ be a set of statements obtained by substituting for each predicate variable in $\mathrm{P}$ some predicate that is significant for a given class of elements $K$; and finally, let $\mathrm{P*}$ consist only of true statements about the elements in K. By a model for P we understand the statements $\mathrm{P*}$, or alternately the system of elements $\mathrm{K}$ characterized by the properties and relations that are designated by the predicates of P*" (NAGEL, 1961, p. 96, note). See also the distinction in Apostel (1961) between "semantic" and "syntactic" models. A chinstein (1968) and Mellor (1968) make the same point in distinguishing linguistic and set-theoretic notions of "model" in mathematical logic. Let us call these two concepts of "model" the S-view and the L-view. In the L-view, a model is any set of propositions (true of some set of objects) having the same formal structurethe same cal culus-as the modeled theory. "M odel" and "theory" arejust different interpretations of the same calculus. B raithwaite (1955) adopts clearly the L-view of "model". Cf. Giere (1999).

8. Suppe says that the predicate "mathematical" used here is, probably, misleading. The expression "mathematical models" stands here simply for semantic models, as in model theory (adopted by C arnap), its scope not being restricted in any way to 
mathematics (SUPPE, 1977, p. 97, note 200). The relevant distinction for Suppe, as I will show in what follows, is between "mathematical" and "iconic" models.

9. Suppe claims that "the prohibition on supplying [theoretical vocabulary] terms with an independent semantic interpretation is limited to observational interpretation and does not prohibit supplying them with nonobservational meaning. Moreover, Carnap and $\mathrm{H}$ empel do make it clear various places that independent nonobservational semantic interpretations are permissible" (SuPPE, 1977, p. 90).

10. Suppe (1977, p. 90, note 191; p. 101, note 211).

11. See note 8.

12. H arré uses the same terminology: "An iconic model stands in for the real mechanism of nature, of which we happen to be ignorant" (H ARRÉ, 1970, p. 52).

13. See Suppe (1977, p. 99, note 208). Cf. H esse's requirements for strongly predictive theories (see note 22, below).

14. Suppe has been one of the proponents (with many others) of what has been called a 'semantic' conception of the structure of scientific theories, presented as an alternative to the 'syntactical' conception (also named the 'standard' or 'received' view of theories-RV). This loose terminology to refer to very different philosophical reconstructions of scientific theories brings a lot of confusion to the debate, though. I won't go into further terminological clarifications, which would depart from my chief concern here. I just mention that in the semantic conception, the notion of 'model' becomes the central one and a theory is not anymore identified with a set of sentences, as in RV. A theory is regarded by the semantic view as a set of models. The semantic view was developed, through many versions, during the 60's and is still an active philosophical program. For a historical overview of these attempts, see Diez \& Lorenzano (2002). I 
discuss the semantic view in the context of Kuhn's work in A brantes (1998b, p. 86). In her 2000 paper, Hesse compares three accounts of theories: the syntactical (or hypotheticodeductive) account, the semantic and the analogical. She argues for the latter one, as I will show below. See also note 18, below.

15. He mentions, in this context, Maxwell's famous definition of "analogy" in "O n Faraday's lines of force" (1855).

16. He is certainly referring here to Maxwell's 1861-2 paper. C $f$. note 15. For historical case-studies on the role different kinds of models and analogies play in science and, especially, in the construction of Maxwell's electromagnetic theory, see A brantes (1998a).

17. Hempel gives also the example of the kinetic theory of gases and its "analogy" with billiard balls.

18. We have here an example of the confusing terminology used to name different philosophical reconstructions of the structure of scientific theories, as I mentioned in note 14. The target of A chinstein's critique here is clearly the notion of a "semantic model", itself a component of later versions of RV (that is, what I have been calling the "syntactical view" of theories) and not what I named, in that note, the "semantic view".

19. M ore recently, H ughes (1997) proposed a triadic "denotationdemonstration-intepretation" account of models, where the internal dynamics of the models is captured by the "demonstration" part of the triad. To model is to represent a kind of system as being of another kind. N ovel predictions are made about the system under investigation by exploring the internal dynamics of the model (which can be of different kinds: material, analogical, mathematical etc.).

20. The main thesis of this paper, however, is that not only "physically imaginable models" (like the forementioned mechanical models) can serve as pointers, but also purely mathematical models: "Theories of a purely mathematical kind may function in 
essentially the same way as physically imaginable models" (H ESSE, 1954 , p. 200). She claims that in contemporary physics, mathematics is the main basis for heuristics and not, anymore, the former kind of models. Here Hesse is clearly not using "mathematical models" in the same sense as Suppe, above (see note 8). Redhead (1980) and Cushing (1982) argue, more recently, for this heuristic role played by mathematical models. In this respect, see al so Steiner (1989), H esse (1966, p. 20, 23). $\mathrm{H}$ esse's later work will be, however, focused on physical models and not on mathematical models.

21. We should distinguish in this context two senses of "formal" (in qualifying analogies and models): Braithwaite's and H empel's. We saw that $\mathrm{H}$ empel claims that nomic isomorphisms can be heuristically useful in suggesting extensions of a theory. In her 1966, H esse talks rather about the first, Braithwaitean sense of a common (formal) structure shared by a model and a theory. We find also characterizations of "material" or "substantial" analogies in N agel (1961), H arre (1970, 1986) and Achinstein (1968), among others. Likewise, H arré claims that "[iconic] models are related to their subjects and to their sources by relations of similarity and difference in material properties. They are to be contrasted with formal or abstract models, which are based on isomorphisms of structure. Model theory in mathematics and the sentential models that are used in some branches of mathematical physics are such formal models. They have their uses too, but play little role in the organization of the intentional objects of middle level theory-families" (H ARRÉ, 1988, p. 120).

22. The distinction between strongly and weakly predictive theories is basic to H esse's account. A theory is weakly predictive when it is able to predict only new relationships between the same observational predicates used already in the formulation of accepted (empirical) laws. H esse calls weakly predictive theories 
"formal theories", referring to RV (1966, p. 38). A theory is strongly predictive when it can predict new relationships involving new observational predicates. This presupposes either changes in the axioms of the theory (changes in Campbell's "hypothesis") or in the correspondence rules (changes in C ampbell's "dictionary"). H esse claims that models based on material analogies are necessarily constitutive of strongly predictive theories. If a theory has no model, changes in the axioms of the theory, or in the correspondence rules, can only be made in an arbritrary way. We saw that Suppe distinguishes this argument for models from the issue of the testability of theories, used by H esse as another argument for the "essential" role models play in science. Suppe claims that an independent semantic interpretation of the theoretical language can account for testability, but not for H esse's "strong prediction" (seeSuppe, 1977, p. 99-100, esp. note 208). Hesse argued for the idea of 'strong prediction' as early as in her 1954 paper (H ESSE, 1954, p. 199). Cf. Braithwaite's distinction s between kinds of 'prediction' (1962, p. 228-229).

23. H essecalls this a "horizontal condition" for analogical modeling.

24. The plausibility of analogical inferences should be, somehow, a function of the ratio of the positive and the negative analogies.

25. In a nutshell we have: M odel $1=$ M odel 2 - (negative analogy).

26. M ore adequately, we should perhaps speak not of a singletheory, but of a "research program" in the sense of Lakatos, or of "theoryfamilies" in the sense of Harre (1986), in which the neutral analogy provides the "positive heuristic" for constructing a series of models, more and more realistic (that is, less and less idealized).

27. See al so Putnam (1962, p. 242-243); Spector (1965).

28. See M ellor (1988, p. 288) and H esse (1980, p. 107-108).

29. I don't have here enough space to develop this large topic. I will just indicatehow it is related to the issue of the (fuzzy) boundaries between the theoretical and observational languages. 
30. In her more recent work, H esse makes explicit the implications of this point: she acknowledges that the similarity basis of relations between object's properties be "either directly perceived" or a consequence of "conceptual resemblances of ideas or pictures derived from preconceived cultural forms" (HESSE, 1988, p. 324-325).

31. See note 40.

32. M ore recently, $\mathrm{H}$ arré keeps mentioning the relevance of Boyd's account of metaphorical language in science: "M etaphor is a trope through which new vocabulary is created. By means of it our conceptual grasp of a subject matter (referent) is enhanced by the use of a term with a well established context of use, and thus an existing deep grammar and set of associated commonplaces. A term used metaphorically is a term used in a new context to express a belief for which there is no existing vocabulary. In using a metaphor we are not comparing the subjects of the attribution of the term in the old and the new contexts, that is looking for similarities and differences between the old and the new extensions of the term. We are not acquainted with the referent of the term in the new context. But perhaps from theory we know some of the things we want to say about it. We are illuminating the new subject by virtue of the existing intension of the displaced term. In the new context that intension will be modified through the exigencies of the new conditions for its uses. In this way, through metaphor, new vocabulary can be created within the existing structure of language, so securing the intelligibility of the term in its new context of use. O nly the displacement theory of metaphor [a term $\mathrm{H}$ arré borrows from Schon] could explain how the use of terms metaphorically could open up the epistemic access which Boyd (1979) has rightly seen to betheir creativefunction" (H ARRÉ, 1986, p. 77). 
33. See, for instance, Goodman (1976, p. 77), Black (1962), Q uine (1994).

34. H esse highlights that there are actually two possibilities here: a) "essential properties" are those engaged in causal relations (in the source theory) with properties in the positive analogy, and/ or; b) essential properties are those engaged in causal relations (in the source theory) with properties in the neutral analogy (H ESSE, 1966, p. 79, 90).

35. This second, "vertical", requirement can be understood as a claim that relations (and not only isolated properties) are central for analogical reasoning. Cf. Gentner (1989) and the privilege she also gives to relations in her simulation of analogical reasoning. I discuss G entner's and other simulations in A brantes (1999).

36. For an in depth discussion of the role Kuhn assigns to exemplars in "normal science", see A brantes (1998b).

37. Lakatos (1978, p. 51) describes the positive heuristics as a "metaphysical' principle". It is remarkable that the popperian tradition, in contrast with logical empiricism, also helped to reintroduce, in the agenda of the philosophy of science, the topic of theoretical dynamics (through Popper's focus on the "growth of knowledge").

38. This approach is salient, for instance, in some of my references to "understanding", "visualization" and "reasoning" in the role played by models in scientific activity.

39. I have developped more fully this approach in other papers (AbRANTES, 1999, 2003), wherel compare several computational simulations of analogical reasoning and used this to account for analogical modeling in the sciences.

40. We can, retrospectively, see H esse's early attempt of accounting for scientific explanation in terms of 'metaphorical redescription' (HESSE, 1966) as compatible with this more general account of analogy-making. See above my discussion of the role metaphors play in science. 
41. This point has been made by many people. See, for instance, Gardenfors, 1990, p. 93-94. Toulmin (1953) suggested that new forms of representation make possible new inferences.

42. Darden (1991) makes the same point by also referring to the CS litterature.

43. C arloye (1971, p. 566), for instance, distinguishes the roles of models as providing revisualizations of the target domain and as a basis for inference. He argues for intermingling them. See also Swanson (1966). Margolis (1993) argues that cognitive processes are acts of pattern-recognition, and apply this perspective to the role played by analogies in the construction of theories: " $N$ ew theories emerge about what lies beyond what we directly perceive, when we see the context as looking like (roughly fitting) some pattern already in the repertoire. $\mathrm{O}$ the argument here, analogy is not one route to discovery, it is the only route" (M ARG OLIS, 1993, p. 153). Indurkhya (1992) makes, fundamentally, the same point.

44. I discussed their proposal elsewere (A brantes, 1999) in more details than I can do in the present paper.

45. A ranson et al. (1995) use resources from AI to implement the notion of 'type-hierarchy' as a representation of one's current ontology. Conceptual schemata and nomic relationships are associated with each type, which is represented as a node in a tree. A major difference between Hesse's and Aranson's accounts of material analogies is that the latter presuppose, besides constraints imposed by the source representation, also constraints imposed by an ontology (represented by a typehierarchy) where the source and the target representations are embedded. G ardenfors' "conceptual space" (1990, p. 83ff) plays basically the same role as a typehierarchy, by constraining which predicates should be considered as "projectible" in inductions and in analogical transfer of information: "A nalogical and metaphorical thinking is another way of establishing the 
similarity of objects. An analysis of these faculties in terms of conceptual spaces may also be helpful in explaining how inductive inferences can transfer information from one domain of qualities to another" (G ARDENFORS, 1990, p. 91).

46. Another example: the predicate "electric displacement" was applied, before Maxwell, just to metals (or, more generally, to matter) and M axwell managed to apply it also to the ether (or, more, generally, to the space that separates bunches of material conductors). The "displacement of electricity" in the ether was not like the unbounded displacement of electricity in material conductors, though. O ne crucial question was: are magnetic effects generated by the displacement of "electricity" in a conductor (metal) also generated by the "electricity" displaced in the ether? Maxwell bet on this hypothesis but he, at first, had no empirical evidence for it. The consequences were, however, dazling: the finite speed of electromagnetic effects in the ether and, ultimately, the identification of those electromagnetic "waves" with the propagation of light. For details, see A brantes (1998a).

Hesse refers to this example in her 1976, p. 8. See also her discussion of the application of the predicate 'hard' in Eddington's "two tables" (1980, p. 106-107). H arre and Gillet (1994) give the example of an abstraction to the type "N ewtonian material objects and their modes of interaction", which is instantiated both in macroscopic objects and in molecules in order to construct a kinetic theory of gases.

47. See al so H esse (1988, p. 336-337).

48. Cf. Black's "interaction view of metaphor" (BLACK, 1962; 1979). This view is discussed by Boyd (1979) and Indurkhya (1992).

49. H esse gives the example of the change in meaning of the predicate 'charge' in her 1980, p. 91-92, in the context of what she calls "the network model of theoretical science".

50. See N ickles (1987b). 
51. I think this was the main motivation behind Hesse's early attempts of explicating modeling as a kind of analogical inference.

52. H elman (1988) provides a broad overview of the importance of analogical reasoning in AI and in CS. See also Vosniadou (1989).

53. I am grateful to the Brazilian Research Council (CN Pq) for a grant that made possible this research.

\section{Bibliography}

Abrantes, P. Imagens de natureza, imagens de ciência. São Paulo: Papirus, 1998a.

. Kuhn e a noção de "exemplar". Principia (Florianópolis), v. 2(1), p. 61-102, jun. 1998b.

Analogical reasoning and modeling in the sciences. Foundations of Science, v. 4, n. 3, p. 237-270, 1999.

- Razonamiento analógico y modelado en las ciencias. In: DuARTE, A.; Rabossi, E. (O rgs.). Psicología cognitiva y filosofía de la mente: pensamiento, representación y conciencia. Buenos Aires: Alianza, 2003, p. 55-98. [Translation into Spanish of Abrantes, 1999].

Achinstein, P. C oncepts of science. Baltimore: Johns H opkins Press, 1968.

A POSTEL, L. Towards the formal study of models in the non-formal sciences. In: Freudenthal, H. (Ed.). The concept and the role of the model in mathematical, natural and social sciences. Reidel: D ordrecht, 1961.

Aronson, J. L.; HarRe, R.; W AY, E. C. Realism rescued: how scientific progress is possible. Chicago: O pen C ourt, 1995.

BAILERJONES, D. Tracing the development of models in the philosophy of science. In: MAGNANI, L. et al. (Eds.). M odel-based reasoning in scientific discovery. $\mathrm{N}$ ew York: Kluwer, 1999. p. 23-40. 
BLACK, M . M odels and metaphors. Ithaca, NY: C ornell U niversity Press, 1962.

M ore about metaphor. In: O RTONy, A. (Ed.). M etaphor and thought. C ambridge: C ambridge U niversity Press, 1979, p. 10-43.

Boyd, R. Metaphor and theory change: what is "metaphor" a metaphor for? In: ORTONY, A. (Ed.). M etaphor and thought. Cambridge: Cambridge U niversity Press, 1979. p. 356-408.

Braithwaite, R. Scientific explanation. Cambridge (Eng.): C ambridge University Press, 1953.

. Models in the empirical sciences. In: NAgEL, SUPPES, TARSKI (Eds.). Logic, methodology and philosophy of science. Standford: Standford U niversity Press, 1962.

Brodbeck, M. Models, meaning and theories. In: Gross, L. (Ed.) Symposium on sociological theory. N ew York: Harper and Row, 1959, p. 373-403.

Cam pbelL, N. R. Physics: the elements. C ambridge: The U niversity Press, 1920.

CARLOYE, J. An interpretation of scientific models involving anal ogies. Philosophy of Science, v. 38, p. 562-569, 1971.

C arnap, R. The logical syntax of language. N ew York: $\mathrm{H}$ arcourt, Brace, 1937.

. Foundations of Logic and M athematics. In: N eU RATH et al. (Eds.). International Encyclopedia of U nified Science. Chicago: The U niversity of C hicago Press, 1939, v. 1, cap. 3.

Press, 1942.

. Introduction to semantics. Cambridge: Harvard U niversity 1966.

. A n introduction to philosophy of science. N ew York: Basic Books,

CUSHING, J. M odels and methodologies in current theoretical highenergy physics. Synthese, v. 50, p. 5-101, 1982. 
Darden, L. Artificial intelligence and philosophy of science: reasoning by analogy in theory construcion. In: NICKLES, T.; Asquith, P. (Eds.). PSA Proceedings. East Lansing (Michigan): Philosophy of Science Association, 1982, v. 2, p. 147-165.

. Al and philosophy of science: reasoning by analogy in theory construction. In: NickLes, T.; AsQuITH, P. (Eds.). PSA, v. 2, p. 147165, 1983.

1991.

. Theory change in science. N ew York: O xford U niversity Press,

Diez, J.; Lorenzano, P. La concepción estructuralista en el contexto dela filosofía dela ciencia del siglo XX. In: Diez \& Lorenzano (Eds.). $D$ esarrollos actuales de la metateoría estructuralista: problemas y discusiones. Buenos Aires: U niversidad N acional de Q uilmes, 2002, p. 13-78.

Freudenthal, H. (Ed.). The concept and the role of the model in mathematical, natural and social sciences. Reidel: D ordrecht, 1961.

Gardenfors, P. Induction, conceptual spaces and AI. Philosophy of Science, v. 57, n. 1, p. 78-95, 1990.

. Induction and the evolution of conceptual spaces. In: MOORE, E. C. (Ed.). Charles Peirce and the philosophy of science. Tuscal oosa: The U niversity of Alabama Press, 1993.

GentNeR, D. The mechanisms of analogical learning. In: Vosniadou, S.; O RTONY, A. (Eds.). Similarity and analogical reasoning. Cambridge: C ambridge U niversity Press, 1989, p. 199-241.

GIERE, R. U sing models to represent reality. In: MaGnANI, L. et al. (Eds.). M odel-based reasoning in scientific discovery. N ew York: Kluwer, 1999, p. 41-57.

G o o Dm An, N . Languages of art. Indianapolis: H ackett Publishing C 0., 1976.

HARRÉ, R. The principles of scientific thinking. London: Macmillan, 1970. 
. Varietes of realism. Oxford: Blackwell, 1986.

. Where models and analogies really count. International studies in the philosophy of science, v. 2, n. 2, p. 118-133, 1988.

Harre, R.; Gillett, G. The discursive mind. Thousand 0 aks (CA): Sage Publications, 1994.

HeLman, D. H. (Ed.). A nalogical reasoning. D ordrecht: Kluwer, 1988. Hempel, C. A spects of scientific explanation. New York: Free Press, 1965.

. Formulation and formalization of scientific theories. In: SU PPE, F. (Ed.). The structure of scientific theories. U rbana: U niversity of Illinois Press, 1977, p. 244-254. A bstract of H empel's 1970 paper: "On the 'standard conception' of scientific theories". In: RADNER \& WINOKUR (Eds.). M innesota Studies in the Philosophy of Science, $\mathrm{V}$. IV, 1970.

Herfel, W. E.; Krajew kski, W.; N in ILU oto, I.; W ójcicki, R. Theories and models in scientific processes. Amsterdam: Rodopi, 1995.

HESSE, M . O perational definition and analogy in physical theories. Brit. J. Phil. Sci., v. 2, p. 281-294, 1952.

. Models in physics. Brit. J. Phil. Sci., v. 4, p. 198-214, 1954.

. Forces and fields. New Jersey: Littlefield, Adams, 1965.

Press, 1966.

. Models and analogies in science. U niversity of N otre Dame

. Models versus paradigms in the natural sciences. In:

ColliNs, Lyndhurst (Ed.). The use of models in the social sciences. London: Tavistock, 1976, p. 1-15.

. Revolutions and reconstructions in the philosophy of science. Bloomington: Indiana U niversity Press, 1980.

. Theories, family resemblances and analogy. In: HeLMAN (Ed.). A nalogical reasoning. D ordrecht: Kluwer, 1988, p. 317-340. 
. M odelsand analogies. In: N EWTON-SM ITH (Ed.). A companion to the philosophy of science. Oxford: Blackwell, 2000. p. 299-307. Hofstadter, et al. Fluid concepts and creative analogies. New York: Basic Books, 1995.

Holyoak, K.; Thagard, P. M ental leaps. C ambridge (M A): The M IT Press, 1995.

Hughes, R. I. G. M odels and representation. In: DARDEN, L. (Ed.). Proceedings of the 1996 biennial meeting of the Philosophy of Science Association, parte II. Philosophy of Science, v. 64 (supl.), n. 4, p. S325-S336, 1997.

Hutten, E. H. O n semantics and physics. Proc. A rist. Soc., v. 49, p. 115-132, 1948-1949. 301, 1954.

. The role of models in physics. Brit. J. Phil. Sci., v. 4, p. 284INDURKHYA, B. M etaphor and cognition. Dordrecht: Kluwer, 1992.

KUHN, T. Second thoughts on paradigms. In: KUHN, T. The essential tension. Chicago: The University of Chicago Press, 1977. p. 293319. [Published originally in 1974].

LaKatos, I. The methodology of scientific research programs. N ew York: C ambridge U niversity Press, 1978.

LeATHERDALE, W.H. The role of analogy, model and metaphor in science. Amsterdam: N orth-H olland, 1974.

MARGOLIS, H. Paradigms and barriers: how habits of mind govern scientific beliefs. C hicago: U niversity of C hicago Press, 1993.

Martin, J.; H ARrÉ, R. M etaphor in science. In: Miall, D. S. (Ed). $M$ etaphor: problems and perspectives. Brighton: $\mathrm{H}$ arvester Press, 1982, p. 89-105.

Maxwell, J. C. On Faraday's lines of force. In: Niven, W. D. The scientific papers of James $\mathrm{Clerk} \mathrm{M}$ axwell. Cambridge: $\mathrm{C}$ ambridge U niversity Press, 1890a, v. I. p. 155-229. 
. O n physical lines of force. In: NIVEN, W. D. The scientific papers of James Clerk M axwell. Cambridge: $\mathrm{C}$ ambridge U niversity Press, 1890b, v. I. p. 451-513.

M CLAU GHLIN, R. Invention and appraisal. In: MCLAU GHLIN, R. (Ed.). W hat? W here? W hen? W hy? D ordrecht: Reidel, 1982, p. 69-100.

M CM u Llin, E. What do physical modelstell us? In. Van Rootselaar, B.; StAaL, J. (Eds.). Logic, methodology and philosophy of science III: Proceedings of the Third Internationcal Congress for Logic, M ethodology and Philosophy of Science. Amsterdam: N orthH olland Publishing Company, 1967. p. 384-396.

MeLLOR, D. H. Models and analogies in science; Duhem versus Campbell?ISIS, v. 59, p. 282-290, 1968.

N AGEL, E. The structure of science. London: Routledge \& Kegan Paul, 1961.

NICKLES, T. Heuristics and justification in scientific research. In: Su PPE, F. (Ed.). The structure of scientific theories. U rbana: U niversity of Illinois Press, 1977, p. 571-589.

. Lakatosian heuristics and epistemic support. B rit. J. Phil. Ści., v. 38, p. 181-205, 1987a.

. Methodology, heuristics, and rationality. In: PITT, J. C.; PERA, M. (Eds.). Rational changes in science. D ordrecht: Reidel, 1987b. p. 103-132.

Putnam, H. What theories are not. In: N Agel, Su pPES, TARSkI (Eds.). Logic, methodology and philosophy of science. Standford: Standford U niversity Press, 1962, p. 240-251.

Quine, W. V. Natural kinds. In: Stalker, D. (Ed.). G rue. Chicago: O pen Court, 1994, p. 41-56.

Redhead, M. Models in physics. Brit. J. Phil. Sci., v. 31, p. 145-163, 1980.

Schaffner, K. Discovery and explanation in biology and medicine. Chicago: The U niversity of C hicago Press, 1993. 
Spector, M. Models and theories. Brit. J. Phil. Sci., v. 16, p. 121-142, 1965.

SteineR, M. The application of mathematics to natural science. Journal of Philosophy, v. 86, n. 9, p. 449-480, 1989.

Su PPE, F. (Ed.). The structure of scientific theories. U rbana: U niversity of Illinois Press, 1977.

Swanson, J. O n models. Brit. J. Phil. Sci., v. 17, p. 297-311, 1966.

TOULmIN, S. The philosophy of science: an introduction. London: Hutchinson, 1953.

Vosniadou, S.; O RTONy, A. (Eds.). Similarity and analogical reasoning. C ambridge: C ambridge U niversity Press, 1989. 